\title{
Regulatory Responses by Countries to Banking/Financial Crises
}

\author{
James R. Barth $\mathbb{D}$ \\ Department of Finance, Auburn University, Auburn, AL 36849, USA; barthjr@auburn.edu
}

Received: 15 December 2019; Accepted: 16 December 2019; Published: 18 December 2019

\begin{abstract}
Banking/financial crises have occurred in countries at all levels of income and in all parts of the world. These crises not only occur too frequently, but also are too costly. Countries everywhere therefore have enacted laws that established regulatory authorities with responsibility to implement appropriate regulations and supervisory practices to promote healthy and stable banking systems. However, relatively recent information has become available that indicates that countries do not choose to regulate and supervise their banks in exactly the same way. Such information helps enable researchers to examine what regulations and supervisory practices work best. The results of these examinations can be extremely important to policy makers when considering changes to make in regulatory regimes in response to the most recent banking crisis.
\end{abstract}

Keywords: banks; bank regulations; banking laws; supervisory practices; financial crises; banking crises; World Bank

The United States (U.S.), a decade ago, suffered its worst banking/financial crisis that contributed to the most severe recession since the Great Depression. The estimated cost of this calamity was more than $\$ 20$ trillion dollars in loss output (Better Markets 2015). Unfortunately, this was not the only banking/financial crisis in the history in the U.S. Indeed, there have been far too many and too costly banking/financial crises over the past two centuries. Certainly, some of these crises were far worse than others, with the two worst occurring in 1930-1933 and 2007-2009. Of course, the U.S. is not the only country in the world that has suffered from financial crises. Crises have occurred in countries at all levels of economic development and in all parts of the world. As a result, countries everywhere have attempted to put in place appropriate financial regulations and supervisory practices to prevent such crises.

In the U.S., and many other countries, the response to every banking crisis has always been the enactment of a new banking law. First, turning to the U.S., Figure 1 provides information on major banking laws enacted and other related information over the period 1780 to 2010. Most, but not all of the laws, were in response or related to a banking crisis. In particular, a few banking laws, including the Bank Holding Company Acts of 1956 and 1970, the Riegle-Neil Interstate Banking and Branching Efficiency Act of 1994, and the Gramm-Leach-Bliley Financial Services Modernization Act of 1999, were mainly in response to changing market developments and not banking crises. 


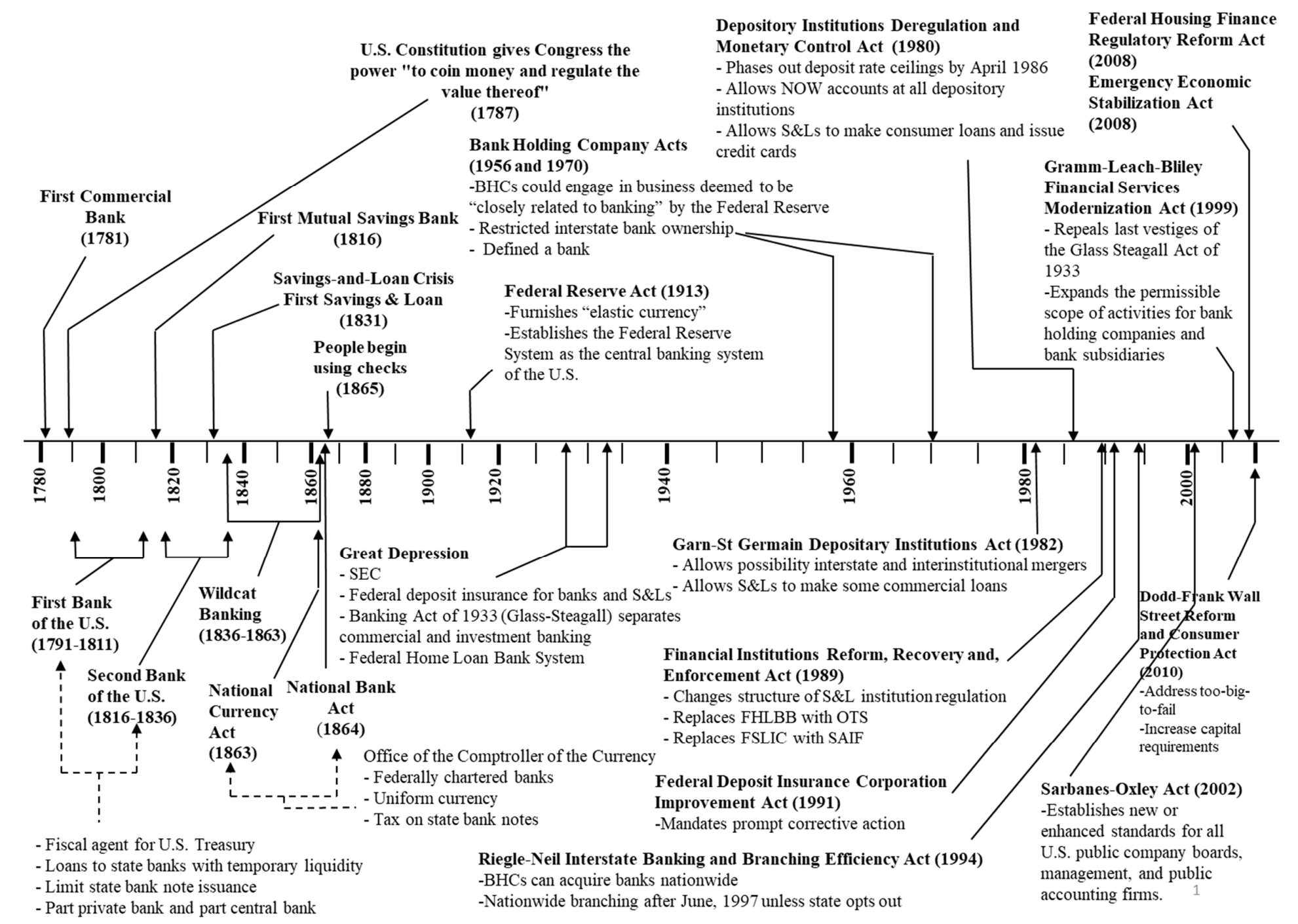

Figure 1. Major U.S. Banking Laws. 
In 1781, as may be seen, the first commercial bank was established. Subsequently, at the time of enactment of laws, the figure provides information about some of the institutions established and regulations implemented. For example, in 1863, the Office of the Comptroller of the Currency was established to charter and regulate national banks, in 1913, the Federal Reserve was established to serve as a lender of last resort, and, in 1933, the Federal Deposit Insurance Corporation was established to provide insurance on deposits to prevent runs on banks. The establishment of these three institutions followed major banking crises. In other cases, the implementation of new regulations followed major banking crises. For instance, the most recent major banking law, the Dodd-Frank Wall Street Reform and Consumer Protection Act of 2010, raised capital requirements for banks and established a sequence of regulatory actions in the event a big bank became troubled so that no bank would be too-big-to-fail.

It is important to emphasize that most of the laws and associated regulations followed major banking crises rather than enacted and implemented, respectively, before such crises. In short, the government has not had the foresight to take the appropriate legal and regulatory actions to prevent banking crises. Indeed, the figure clearly shows that after every crisis the action taken was insufficient to prevent a subsequent banking crisis. Over time, the result has been more regulators and more regulations imposed on banks. Worse yet, some might say, the process of banking crises followed by laws and regulations is a never-ending process. If so, this means one might expect another banking crisis and the same regulatory response in about 20 years.

Second, turning to other countries, many of them suffered banking crises at the same and different times. Most, if not all, of them also enacted laws and associated regulations to prevent future banking crises. In this regard, in the early 2000s, the World Bank created a global database of bank regulation and supervision (Barth et al. 2001). The second update of the database was issued in 2003, the third in 2007, the fourth in 2012, and the fifth in 2019 (World Bank 2020). The databases were created based on surveys of countries around the world in which questions were sent to and answers received from the appropriate government bank regulatory agencies. The most recent survey was a major revision of earlier surveys. However, it retained several questions from the first survey to maintain comparability over time. Still other questions were reformulated and included to generate more precise answers and to elicit information on macroprudential regulation and consumer protection.

The most recent database contains important information on the way in which 159 countries regulate and supervise their banks. Importantly, the database shows that there are, in many cases, substantial differences among the respondent regulatory agencies. Information is provided about capital requirements, deposit insurance systems, resolution of troubled banks, market discipline, among other important regulatory and supervisory topics. Given the importance of capital requirements, it is interesting to see the differences among the countries with respect to following each of the three Basel regimes, Basel I in 1988, Basel II in 2004, and Basel III in 2010 (Barth and Miller 2018). As Figure 2 shows, there are substantial variation depending upon the region of the world in which the respondent countries are located. The High-income OECD countries most frequently follow Basel III (91\%), which includes the U.S. In contrast, only $10 \%$ of the Sub-Saharan Africa countries follows Basel III.

Figure 3 provides information on tools used by countries to compliment capital requirements. As may be seen in panel a, a greater percentage (89\%) of banking supervisors in High-income countries conduct stress tests as part of systemic stability assessments than in Developing countries $(74 \%)$. In addition, as panel $\mathrm{b}$ shows, $77 \%$ of High-income countries impose countercyclical capital buffers on banks, while only $25 \%$ do so in Developing countries. Moreover, in panel c, a relatively high percentage $(85 \%)$ of High-income countries have introduced a liquidity coverage ratio, while a relatively low percentage (30\%) of Developing countries have done the same. Also, in panel c, roughly few (13\%) High-income countries have introduced a net stable funding ratio, while even fewer (3\%) Developing countries have done the same. 


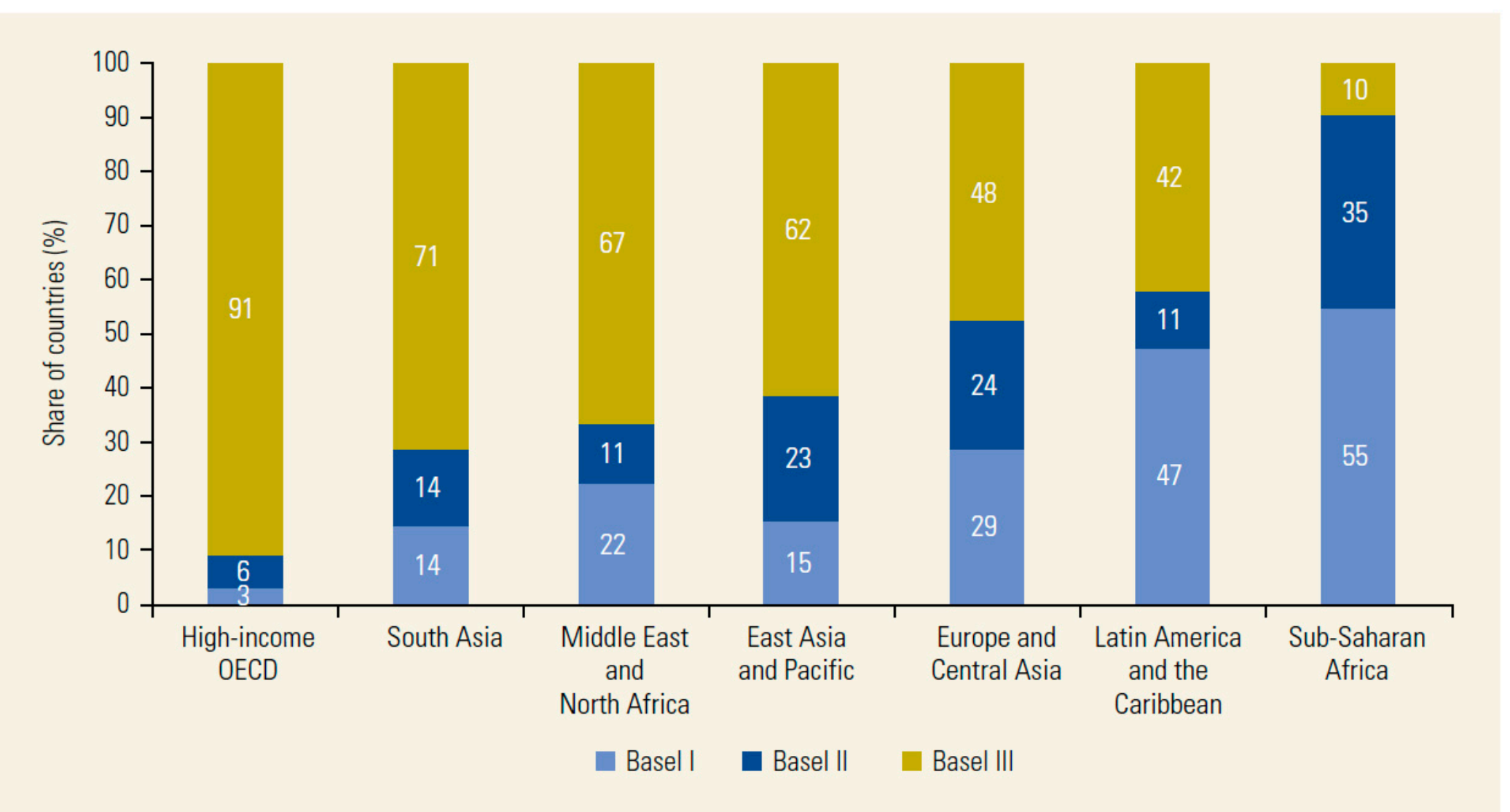

Figure 2. Percentage of Countries Following Each Basel Regime, by Region. Source: Bank Regulation and Supervision Survey (BRSS), the most recent survey, https://www.worldbank.org/en/research/brief/BRSS. Note: This figure is based on 2016 data from 133 countries. Not all high-income OECD countries use Basel III. Chile follows Basel I, and Austria and Latvia follow Basel II. OECD = Organisation for Economic Co-operation and Development. 


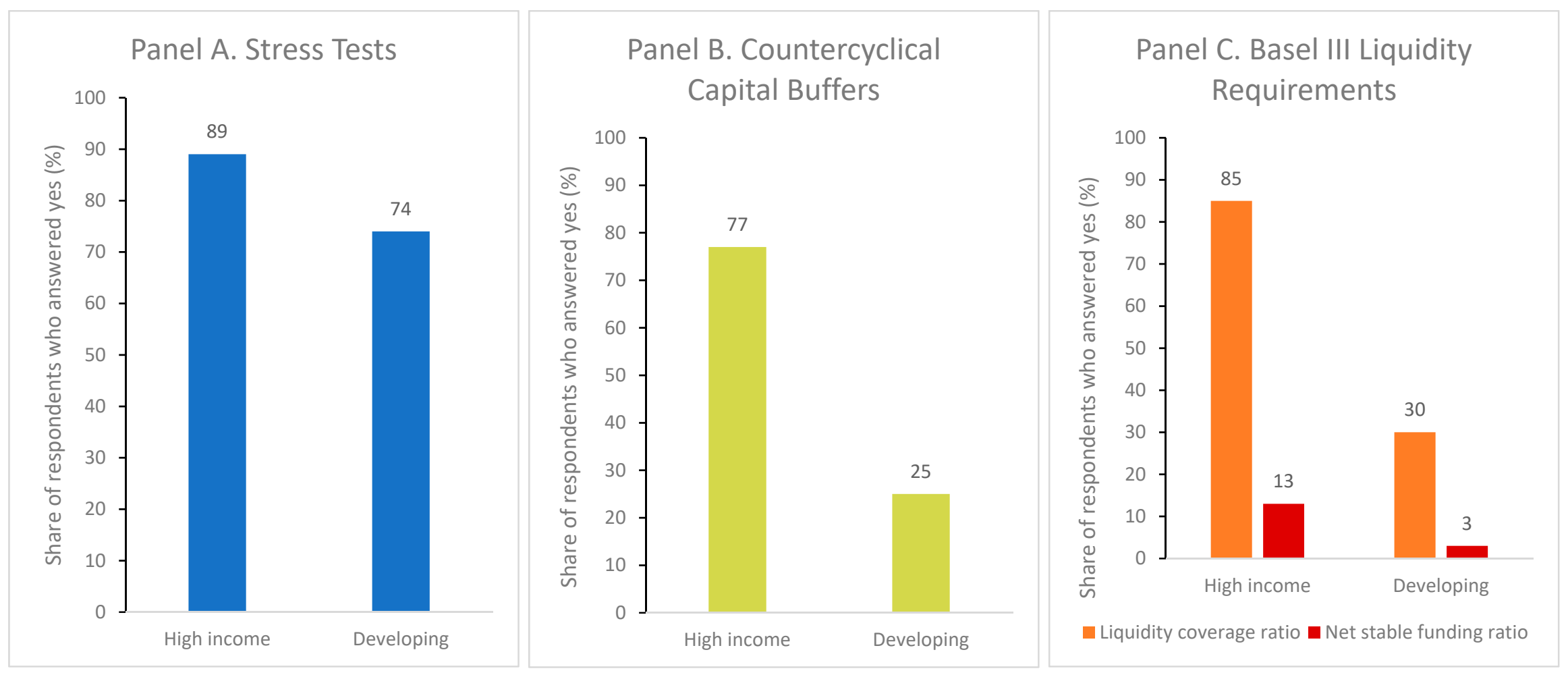

Figure 3. Capital Regulations: Complementary Tools. Panel A shows percent of respondents answering yes to whether banking supervisor conducts stress tests as part of systemic stability assessments. Panel B shows percent of respondents answering yes to whether there are countercyclical capital buffers. Panel C shows percent of respondents answering yes to whether Basel III liquidity requirements have been introduced. Source: Bank Regulation and Supervision Survey (BRSS), https://www.worldbank.org/en/research/brief/BRSS. Note: The questions reported in panels b and c were introduced in the most recent survey of the BRSS. 
It is essential in many banking research projects to have information about how countries regulate and supervise their banks. It is only in this way that one is better able to examine what specific regulations and supervisory practices work best to promote healthy bank performance and financial stability (Barth et al. 2004). In this regard, if one focuses on a single country like the U.S., then one needs information over time such as that in Figure 1, and in some cases even more detailed information, in an attempt to determine what works best. To examine what works best one might find it even better to rely on the type of information collected and made publicly available by the World Bank, as described above. Insofar as banking crises, or financial crises more generally, occur too frequently and are too costly, research relying upon the databases discussed here, among others, are quite important in assessing the best way to regulate banks, or financial firms more generally, can provide essential information for policy makers. Of course, one has to realize that not all countries have to rely on the same regulations and supervisory practices to promote a healthy and stable banking system.

Funding: This research received no external funding.

Acknowledgments: The author is extremely grateful to Min Gu, Nguyen Nguyen and Jiayi Xu for excellent assistance in the preparation of this editorial.

Conflicts of Interest: The author declares no conflict of interest.

\section{References}

Barth, James R., Gerard Caprio, Jr., and Ross Levine. 2001. The Regulation and Supervision of Banks around the World: A New Database. Policy Research Working Paper WPS2588. Washington, DC: World Bank.

Barth, James R., Gerard Caprio, Jr., and Ross Levine. 2004. Bank Supervision and Regulation: What Works Best? Journal of Financial Intermediation 13: 205-48. [CrossRef]

Barth, James R., and Stephen M. Miller. 2018. On the rising complexity of bank regulatory capital requirements: From global guidelines to their United States (US) implementation. Journal of Risk and Financial Management 11: 77. [CrossRef]

Better Markets. 2015. The Cost of the Crisis. Available online: https://bettermarkets.com/sites/default/files/Better\% 20Markets\%20-\%20Cost\%20of\%20the\%20Crisis_1.pdf (accessed on 13 December 2019).

World Bank. 2020. Bank Regulation and Supervision a Decade after the Global Financial Crisis. Global Financial Development Report. Washington, DC: World Bank. 